\title{
A CONSTITUIÇÃO DO LIVRO DIDÁTICO DA ERA MODERNA - ENSAIO SOBRE ISSUN BÔSHI - O MITO DO SURGIMENTO DO ADULTO
}

Masatsugu Aoki *

Consideremos o conteúdo indicado pelo livro didático, enquanto expressão conceitual, como a expressão do modelo de desenvolvimento temporal daquele que vive na sociedade moderna, através da idéia de natureza. Ou seja, trata-se da expressão que, mediante narrativas, manifesta uma forma definida da idéia de homem. Tal forma de expressão age de tal modo que o próprio ato de lê-lo resulte em aceitar como instituição a idéia denominada homem. Em outras palavras, é o surgimento do papel do livro didático, na qualidade de usos e costumes. Naturalmente o homem a que me refiro aqui é o homem asiático, o homem natural da era moderna asiática.

Issun Bôshi ${ }^{\star \star}$ é, antes de tudo, a narrativa do tornar-se adulto. Em primeiro lugar, o homem é um ser que deixa a condição de algo anterior à criança (caráter de raça estrangeira da antiguidade) para literalmente "fazer-se homem", ou seja, surgir, como se fosse divindade, em forma de adulto (homem moderno-homem feito). Como reflexo oposto da idéia de adulto, forma-se, posteriormente a idéia de criança. Portanto, ela narra, antes de mais nada, o nascimento do adulto.

Em seguida, Issun Bôshi é também uma narrativa de ascensão social. Nela, o conceito de adulto ainda está envolto na idéia de nobre das narrativas da antiguidade. Isto porque encontra-se restrito à extensão que o poder real alcança. O homem, embora já tenha deixado de ser divindade, ainda é um ser que deve ascender (aparecer) da condição de casta baixa.

Issun Bôshi é, ainda, a narrativa de transformação da casta baixa anexa à aldeia, que vai se manifestando em forma de povo urbano. Ele precisa se transformar, da classe de atores (casta baixa), anexa às aldeias 
da antiguidade (povo agrícola), em cidadão, povo vivente em geral, digno do espaço monetário chamado urbe moderna - para se tornar homem.

E a sua transformação precisa acontecer de modo que se torne homem ao nivel do corpo e crie a concepção de corpo. A frase, "tinha três centímetros de altura", referente a Issun Bôshi, não tem nenhuma relação com a concepção de ordem física, mas representa apenas os seres estranhos ou as divindades.

E, por fim, ele precisa contrair o matrimônio, que é o nascimento ao nivel urbano. $O$ seu surgimento na aldeia foi o primeiro nascimento, e isso indicava que se tratava de um ser que visitava as aldeias como divindade ou estrangeiro. $O$ segundo nascimento torna-o publicamente um ser sexual. $O$ fato de ele próprio se revelar encarnando o sexo, e não como um ser que anda intermediando o sexo na calada da noite, constitui o ritual chamado matrimônio (mostrar o aspecto do ponto de partida).

O que intermediou o surgimento dessa idéia natural chamada homem. ou o que provocou tal recomposição do sentido, foi a mídia, que alcançou o nivel de expressão chamado moeda. A mídia é a expressão da força de alienação do homem em relação a si mesmo (a expressão de si mesmo que se transformou em representação e passou a se revelar em oposição ao próprio homem, assumindo um aspecto social). Isso revela o estágio em que chega à moeda, após passar por alimentos (animais e frutos; arroz) e pepitas de ouro e prata.

A narrativa Issun Bôshi não mostra apenas o processo de nascimento do homem moderno asiático que está neste estágio, em forma de instituição (idéia natural). Conforme esta idéia natural, nasce com o papel de refletir a própria imagem no espelho. Em outras palavras, ela é a literatura enquanto instituição moderna. Tradicionalmente, o conceito moralístico de Otogizôshi (narrativas de entretenimento) ou de Kanazôshi (histórias escritas em kana) indica o nascimento destes livros didáticos, que são literatura enquanto instituição.

Nesta narrativa, 0 adulto (homem pré-moderno) surge no final. $O$ nascimento do adulto é o objetivo da narrativa e encontra-se no final do fluir do tempo. A cena do começo da história, que parece ser o nascimento de Issun Bôshi, não indica o nascimento, mas sim a revelação (aparecimento de divindades ou de estrangeiros). "Tiveram um menino gracioso, entretanto, como depois de nascido tinha três centímetros de altura, deram-lhe o nome de Issun Bôshi." - Este trecho nos mostra que o casal de anciãos recebeu das divindades algo (segundo a concepção de raça estrangeira da antiguidade, seria a divindade ou o estrangeiro) que no final desta narrativa vai se 
transformar em adulto. $\mathrm{O}$ que está oculto por trás da maneira de representá-lo como raça anã (a expressão "três centímetros") ou como raça de divindade (a expressão "hôshi"), é aquilo que deverá vir se revelando como concepção de criança na época posterior.

Naturalmente nesta narrativa não se lê esta concepção oculta da criança. Lê-se rigorosamente a idéia de adulto e o processo da própria metamorfose por que deve passar para chegar aí. Nesse sentido, ler significa descobrir-se a si próprio e doutrinar-se a si mesmo. O livro didático deve ser lido com esta atitude. O que o folclore e a antropologia lêem nela deve ser o caráter estrangeiro, mas o que o sistema literário lê é a imagem da idéia natural que expressa a nossa devida imagem.

\section{(1) Estrutura temporal}

A narrativa Issun Bôshi possui a estrutura temporal definida como mostramos a seguir:

(1) Surgimento na aldeia

(2) Expulsão da aldeia

(3) Entrada para a Capital

(4) Saída da Capital

(5) Entrada para a ilha

(6) Entrada para o palácio

O processo de tornar-se adulto é visto aqui como uma constante mudança de espaço de vivência. Tornar-se adulto significa o fim desta peregrinação, a entrada para uma vida com residência fixa. Isto expressa bem a essência da concepção da natureza "asiática". Ela tem como base o juízo de que o homem nasce e morre dentro de um mundo cíclico espacial. A estrutura desta narrativa é feita de modo que chegue a esta cognição do homem, termine no momento em que o peregrino se torna residente permanente. Significa que, conforme vai-se trocando de local para morar, em busca de um lugar onde possa fixar residência, chega-se ao homem capaz de fixar residência, ou seja, ao adulto.

A forma original da imagem do mundo cíclico asiático (da pré-antiguidade) são as específicas montanhas e florestas africanas (primitivas). É o mundo externo que faz a aldeia tomar forma, como se a refletisse no espeIho. Certamente isso representa a idéia do sexo (mulher). No estágio asiá- 
tico, o sexo, na qualidade de mãe animal mostra-se fragmentado entre a montanha e a aldeia. Acredita-se que nesse momento a montanha ou a floresta específicas, que representam o mundo externo, são abstraídas em uma rocha gigante situada sobre a montanha ou em uma árvore (árvore gigante) que fica no meio da floresta, formando a concepção da maternidade (animal) que ai se aloja.

\section{Caráter de estrangeiro - Em torno da aldeia}

O ancião e a anciã, que aparecem no início da narrativa, devem ser a representação sexual da raça estrangeira que pertence às aldeias da antiguidade. Eles são de uma raça estrangeira desprovida da maternidade, que é a concepção sexual da aldeia asiática. $O$ algo que deverá surgir posteriormente como adulto surge no meio desta raça estrangeira. Não foram o ancião e a anciã que o geraram; eles receberam-no após orarem às divindades. Ele surgiu como reflexo e expressão dessa falta de maternidade (modo de ser não-asiático). O que está anexo no lado de fora da aldeia é a idéia de familia.

\section{(2) Tornar-se estrangeiro - Saída da aldeia}

Issun Bôshi é o nome dado ao estrangeiro que surgiu no meio da raça estrangeira, não pertencente à aldeia (concepção de família constituída pelo casal de anciãos) que reflete a aldeia não-asiática. $O$ estrangeiro é a imagem da própria raça estrangeira. Isso é a imagem hipertrofiada do excesso (lixo) da aldeia (raça estrangeira = família) que chega a se opor à própria aldeia. Naturalmente, a aldeia precisa expulsá-lo do seu próprio âmbito e também do seu anexo (raça estrangeira), para expressar a substância da imagem do lixo hipertrofiado.

"Não é um ser humano comum. Deve ser mesmo algo parecido com demônio. Queremos mandá-lo embora, para onde quer que seja." - Dessa maneira, Issun Bôshi é rejeitado pelo casal de anciãos, e ele próprio, resignado, deixa a casa dizendo: - "Aflige-me o fato de ser considerado desta maneira até pelos pais. Quero ir embora, seja para onde for." O caráter demoníaco refere-se ao fato de manter permanentemente o caráter da raça anã, como se depreende do trecho: "Criaram-no até completar 12 ou 13 anos, mas nem mesmo a sua altura é normal." Isso significa que o dito adulto surge como um ser que sustenta as particularidades físicas. Não é 
a criança que o faz; é rigorosamente o fato de se tornar adulto que vem se expressando dessa forma.

O adulto é considerado como um ser que não só é rejeitado, assim, pelos pais, mas também que se posiciona como um ser que aceita essa rejeição, deixa a casa por sua iniciativa e traduz isso em atos. Como reverso da revolta contra a família (o fato de ser raça estrangeira da aldeia) ou do auto-abandono, a idéia do crescimento autônomo, que é começar a dirigir os olhos para o vasto mundo, é expressa como um processo natural. Isto é a expressão da instituição denominada ego.

\section{(3) Transformação em ator - Entrada para a Capital}

O destino (situado fora da aldeia), ao qual aquele que foi expulso da família quer chegar, é a Capital. A entrada para a Capital é o processo pelo qual o estrangeiro anão deixa a raça estrangeira, anexa à aldeia, e é abstraído para o espaço da Capital (urbe antiga). Isso expressa o fato de os artesãos ou as divindades que permanecem nas cercanias da aldeia, irem se transformando em atores da Capital. Isso mostra a mudança de posição em que eles próprios passam a expressar a contradição entre a concepção antiga (divindade) que eles carregavam e a natureza (meios de vida). Esta abstração de si próprio é expressa pelo fato de ser reconhecido pelos citadinos como indivíduo interessante. Que tipo de relação expressa a palavra "interessante"?

Está escrito que, quando Issun Bôshi foi à Corte e disse: "Gostaria de dizer uma coisa", o primeiro-ministro considerou ser uma "voz interessante" Isso indica a relação de desencontro, em que um está transmitindo (o sentido) a palavra, enquanto o outro está recebendo essa voz. Além disso, ambos não negam essa relação e a aceitam como tal. A contradição entre a alma da expressão verbal (caráter divino) e a voz (caráter instrumental) não é nem negada, nem rejeitada, sendo que o próprio desencontro é visto como interessante enquanto relação. Como o conceito desse tipo de relação não existe na cultura ocidental (Antiga/Moderna) não há dúvida de que, segundo os conhecimentos ocidentais, isto foi considerado um humor de alto nivel, abstraído e interpretado erroneamente.

A concepção de arte (arte de entreter, não artes plásticas) demonstra um modo de inter-relacionamento onde se preserva como relação o próprio desencontro de relações. A conotação peculiar do termo "interessante" está expressando isso. A Capital é o lugar onde o caráter estrangeiro (o excesso, o lixo, da sociedade aldeã) é reconhecido oficialmente como "algo interes- 
sante" Isto significa que o adulto surgiu inicialmente como esse "ser interessante" (ator).

E este caráter interessante (arte) é expresso da seguinte maneira: "Debaixo do tamanco, disse: 'Não pise na gente'" A inversão do ser que calça o tamanco (divindade) para o ser que tem o tamanco sobre a cabeça (casta baixa), nos sugere o abandono do caráter mediúnico da raça anã, mediante o destaque do seu caráter físico. A arte (do entretenimento) está no caráter físico desprezível daquele que está para se tornar adulto, fazendo com que as pessoas recebam isso como interessante.

\section{(4) Transformação em comerciante - Na Capital}

$\mathrm{Na}$ urbe antiga (Capital) o adulto era ainda um ator. Para se tornar ainda mais adulto ele precisa partir para a urbe moderna. Como é expresso esse lugar, que fica além da Capital? Esse lugar é expresso como possivel de ser alcançado no momento em que o ator percebe a relação de desencontro de ser considerado ator pelos outros, quando ele próprio não se considera como tal e, passa a utilizar conscientemente essa relação desencontrada como a sua própria capacidade.

A conscientização da sua arte constitui-se na idéia de ego que o adulto deve possuir, mas de que maneira é expressa essa conscientização?

Issun Bôshi, "desde que viu a princesa" (filha do primeiro-ministro), passou a pensar só nela e a querer fazer dela sua esposa, arquitetando os planos. Esse ato de arquitetar planos constitui a realização consciente da arte. Esta arte consiste em colar grãos de arroz em volta da boca da prince$\mathrm{sa}$, enquanto ela dorme e fingir que chora, queixando-se que fora roubado. O furto, pela lei da Capital, é punido com o exílio, e o destino da princesa foi entregue nas mãos de Issun Bôshi. Assim, ele a obtém. Podemos dizer que esta arte consiste em logro (ato de enganar).

Isto é o mesmo que o ato mercantil dos traficantes de escravos (a arte de enganar) que aparece freqüentemente nos contos da Idade Média. A conscientização da arte, que consiste em manter voluntariamente o desencọntro da relação entre eu e o outro, embora para os próprios envolvidos seja um desencontro em que um engana e o outro é enganado, é fazer com que o logro seja aceito e sentido como "interessante" pela sociedade. $O$ comércio e a capitalização seriam a oficialização, perante a lei, dessa relação de desencontro. É criar um novo mundo natural chamado comércio, fora da Capital (mundo da arte). 
Isso é a urbe moderna. A contradição entre a aldeia e a Capital da sociedade antiga é que cria um novo universo fora do confronto entre elas. A contradição (expressão) da relação entre a aldeia e a Capital é a princesa. Ela é, para a Corte, uma riqueza da antiguidade e indica o núcleo oculto que faz a própria Capital, o tesouro (maternidade) acumulado no "interior" da Capital (Palácio). Esta riqueza da antiguidade deverá ser retirada do seu depósito pelos comerciantes e transformar-se em capital. A maternidade transformada em capital surge em forma de prostituta e esposa. $O$ espaço chamado maternidade (imagem do mundo cíclico) é temporalizado e tornase energia ativadora da sociedade. Quem transforma a riqueza da antiguidade em capital moderno é a arte do comerciante. Trata-se da arte de enganar, que consiste em levar a princesa para fora da Capital em conformidade com a lei.

\section{(5) Transformação em adulto - Na ilha}

O mundo externo à Capital (urbe antiga) é representado como uma ilha misteriosa e estranha. Se for um conto folclórico, ele se manifesta como "Oniga shima", e se for uma lenda ideativa, "Hôrai no shima" Esta imagem de ilha deve ter origem na "montanha ilhada" que é o protótipo primitivo da comunidade asiática (da pré-antiguidade). É uma imagem espacial das condiçōes naturais que constituem a aldeia isolada e auto-suficiente, onde se vê o mar à frente, e as montanhas logo atrás. Nela existe o modo de vida baseado na caça e na agricultura, e o povo vive com a idéia da metamorfose em que os animais e os frutos, que são a mãe, vão sendo transformados em produtos agrícolas, e cultuam essa imagem maternal deificada e simbolizada em rochas e árvores gigantes.

Se dissermos que a imagem da urbe moderna é o lugar onde estão confinadas a Capital antiga e a ilha (shima) que fica fora dela, vem-nos imediatamente à mente a imagem de locais como Edo ou Osaka que comportavam um espaço reservado aos prostíbulos (shima), tais como Yoshiwara e Sonezaki.

$\mathrm{Na}$ ilha há dois demônios. Um deles tem um maço mágico (uchide no kozuchi), e o outro tenta arrebatar a princesa engolindo Issun Bôshi. Eles representam o poder de conversão do significado (valor) que a urbe moderna (ilha) tem. $O$ demônio é o mundo externo à Capital da antiguidade (imagem invertida da aldeia) representado em forma de uma força típica da antiguidade, e esta, quando representada em forma de lugar, torna-se ilha. Como esta força da urbe moderna é expressa através das duas faces da raça es- 
trangeira da antiguidade, que são o caráter instrumental da arte (caráter de artífice) e o caráter artístico físico da arte (caráter de acrobata), tem-se as expressões como "maço mágico", ou "engoliu-o pela boca, e ele saiu de dentro dos olhos"

O maço mágico e o corpo do demônio indicam a força conversora que convertem o significado das forças motrizes da sociedade antiga, que são a riqueza chamada princesa e o traficante de escravos, em capital e trabalho modernos.

O fato de "engolir e vomitar", da mesma forma que o fato de sacudir o maço mágico gera o que antes não existia (não era visivel). A força motriz da antiguidade (demônio) é abstraída na capacidade de transformar voluntariamente a si mesmo, como por exemplo de sacudir ele próprio o maço mágico, ou de passar livremente pelo corpo do demônio por sua iniciativa. Isto é o que chamamos de ego. É a capacidade de transformar a si mesmo em adulto.

O crescimento físico (tornar-se adulto fisicamente), o fato de fazer aparecer uma comida apetitosa porque se cansou, (viver através da mercadoria chamada alimento que nutre o corpo), e o fato de fazer aparecer "ouro e prata" (moedas) e, junto com a princesa (casamento), ir para a Capital (tornarse cidadão da urbe moderna), são apresentados como condições do homem moderno (adulto).

\section{(6) Tornar-se citadino - No palácio}

A última condição que se impõe a Issun Bôshi, que se tornou adulto, é ser reconhecido oficialmente como tal e tornar-se modelo, como "exemplo de indivíduo bem-sucedido" O reconhecimento oficial é feito pelo Imperador. Está escrito: "Sua Majestade o viu e disse: 'É um jovem muito belo' " reconhece, desse modo, o adulto como um citadino. E o ritual que se segue, de perguntar pelos antepassados é apenas a manifestação pública do citadino à moda de contos antigos.

A capacidade de crescer por si e a criação (descobrir o ego original) podem ser consideradas o tema principal desta história do homem moderno (adulto). A diferença entre esta narrativa e as histórias típicas da antiguidade (em que um ente elevado é expulso do céu, vive junto com os seres inferiores e, posteriormente, volta ao céu, num final feliz) está no fato de a personagem não apenas aceitar e responder à situação imposta pelo destino, 
mas possuir a força e a arte de usar e transformar essa situação. Ele incorpora a riqueza em capital, transformando a situação em energia.

A personagem materializa o caráter divino da antiguidade (caráter estrangeiro da pré-antiguidade) que possuía quando surgiu neste mundo, e vai abstraindo em forma de energia (ego) que the permiti transcender o delimitado espaço asiático. Ele vai mudando de lugar sucessivamente, ascendendo socialmente. Ele encarna o processo de transformação da riqueza estática da antiguidade em capital dinâmico da era moderna, o ego é o capital incorporado e o adulto é aquele que transforma o físico com a capacidade de materializar a situação da antiguidade (espaço).

(Texto original em japonês) 